\title{
Evaluation of the effects of spray drying parameters for producing cubosome powder precursors
}

von Halling Laier, Christoffer; Alstrøm, Tommy Sonne; Bargholz, Mia Travers ; Sjøltov, Pernille Bjerg ; Rades, Thomas; Boisen, Anja; Nielsen, Line Hagner

\author{
Published in: \\ European Journal of Pharmaceutics and Biopharmaceutics
}

Link to article, DOI:

10.1016/j.ejpb.2018.12.008

Publication date:

2018

Document Version

Peer reviewed version

Link back to DTU Orbit

\section{Citation (APA):}

von Halling Laier, C., Alstrøm, T. S., Bargholz, M. T., Sjøltov, P. B., Rades, T., Boisen, A., \& Nielsen, L. H. (2018). Evaluation of the effects of spray drying parameters for producing cubosome powder precursors. European Journal of Pharmaceutics and Biopharmaceutics, 135, 44-48.

https://doi.org/10.1016/j.ejpb.2018.12.008

\section{General rights}

Copyright and moral rights for the publications made accessible in the public portal are retained by the authors and/or other copyright owners and it is a condition of accessing publications that users recognise and abide by the legal requirements associated with these rights.

- Users may download and print one copy of any publication from the public portal for the purpose of private study or research.

- You may not further distribute the material or use it for any profit-making activity or commercial gain

- You may freely distribute the URL identifying the publication in the public portal 


\section{Evaluation of the effects of spray drying parameters for producing cubosome powder} precursors

4 Christoffer von Halling Laier ${ }^{a^{*}}$, Tommy Sonne Alstrøm ${ }^{a, b}$, Mia Travers Bargholz ${ }^{a}$, Pernille Bjerg $5 \quad$ Sjøltov ${ }^{a}$, Thomas Rades ${ }^{c}$, Anja Boisen ${ }^{a}$, Line Hagner Nielsen ${ }^{a}$

6 aDepartment of Micro- and Nanotechnology, Technical University of Denmark, Oersteds Plads 7 345C, 2800 Kgs. Lyngby, Denmark

$8{ }^{b}$ Department of Applied Mathematics and Computer Science, Technical University of Denmark, 9 Richard Petersens Plads 321, 2800 Kgs. Lyngby, Denmark

$10{ }^{c}$ Department of Pharmacy, Faculty of Health and Medical Sciences, University of Copenhagen, 11 Universitetsparken 2, 2100 Copenhagen, Denmark

\section{Keywords}

14 ovalbumin, particles, colloids, monoolein, vaccine, design of experiments

\footnotetext{
${ }^{*}$ Corresponding author: Department of Micro- and Nanotechnology, Technical University of Denmark, Oersteds Plads 345C, 2800 Kgs. Lyngby, Denmark.

Phone: +45 452557 87, E-mail: cvohal@nanotech.dtu.dk (C. von Halling Laier)
} 
18 Vaccines provide great benefit for global health, but are insufficiently distributed in developing

19 countries due to high costs of manufacturing and limited storage stability. Spray drying

20 formulations of peptide-based vaccines offer a promising strategy to reduce production costs and

21 improve unrefrigerated storage stability. This design of experiments investigated how adjusting

22 spray drying parameters (inlet temperature, atomization pressure, feed rate and aspiration rate) affects residual moisture and reconstitution properties of the powder product, and morphology and size of the rehydrated particles. An emulsion capable of forming cubosomes with the protein ovalbumin as model antigen was used as vaccine formulation and spray dried. The produced powders had low residual moisture content, independent of the spray drying parameters within the range investigated. Cryogenic transmission electron microscopy revealed that cubosomes were produced after rehydration regardless of the spray drying parameters. Furthermore, dynamic light scattering showed that the average diameter of the rehydrated particles consistently was close to 230 $\mathrm{nm}$ at any combination of spray drying parameters as long as the outlet temperature was kept below a threshold of $115^{\circ} \mathrm{C}$. The process thus appears to be robust allowing optimization to be focused on yield, dry particle engineering or outlet temperature considerations. 


\section{Introduction}

Vaccines are a cost-effective medical intervention with great positive impact on global human health [1]. However, they remain insufficiently distributed in developing countries due to factors such as the high costs of manufacturing and the challenges of cold-chain distribution [2]. A promising method for improving vaccine stability is to use peptides instead of conventional whole organism antigens followed by drying the vaccine formulation $[2,3]$.

To provide effective immunization, peptides need to be delivered in a particulate delivery system [1]. Cubosomes are lipid-based nanoparticles that have been shown in vivo to be a promising delivery system for vaccination [4,5]. They are composed of a highly twisted continuous lipid bilayer with three-dimensional long range order forming two discrete but highly tortuous water channels [5]. Cubosomes are traditionally produced as dispersions in water by fragmentation of bulk cubic phase liquid crystals (top-down) or by self-assembly of certain amphiphilic lipids upon solvent dilution in water (bottom-up) [6]. Recently, however, spray dried cubosome precursors containing the protein ovalbumin (OVA) - a commonly used model peptide antigen - have been reported to form cubosomes in the size-range of 200-300 $\mathrm{nm}$ after hydration [5,7]. These cubosomes could furthermore be co-delivered with the adjuvant Quil-A with little effect on their structure and size and were able to stimulate strong humoral and cellular immune responses [5].

\section{Spray dried vaccine formulations are easier and cheaper to transport compared to liquid} formulations and can offer increased storage stability [5]. Attenuvax ${ }^{\circledR}$ is a lyophilized commercial live-attenuated measles vaccine from Merck Sharp and Dohme Corp. Its product package insert indicates that the storage stability is 24 months at $2-8^{\circ} \mathrm{C}$, but is reduced to 1 week at $37^{\circ} \mathrm{C}$ and should be used within a maximum of $6 \mathrm{~h}$ after reconstitution [8]. Ohtake et al. reported on using spray drying to produce a powder formulation of a similar measles vaccine that was eight times more stable at $37^{\circ} \mathrm{C}$ than the commercial lyophilized product [8]. Spray drying is a process in which a liquid feed is atomized into small droplets within a flow of hot air, resulting in fast evaporation of the solvent and formation of dry particles [3]. The method is simple, inexpensive and usually easy to scale up. Spray drying furthermore offers the possibility of high throughput production and is well suited for drying labile compounds. Therefore, it is a promising method for drying of vaccines $[5,8]$. However, changes in spray drying parameters aimed to optimize e.g. the yield may affect product properties such as the particle size. Similarly, up-scaling the production process to a commercial type spray drier will inevitably affect the drying parameters necessitating re-validation of the method and possibly expensive optimization work at the large scale. A nanoparticle system that is robust to changes in spray drying parameters is therefore desirable. However, comprehensive studies of the robustness of spray drying processes for pharmaceutical nanoparticulate formulations are rare.

The aim of this study was to investigate how the spray drying parameters (inlet temperature, atomization pressure, feed rate and aspiration rate) affect selected properties of a cubosomes formulated with ovalbumin. Powder product characteristics investigated in this study are the residual moisture and the powders ability to reconstitute. Following reconstitution, the size and morphology of the hydrated particles was measured. The study also evaluated two process parameters, namely the outlet temperature and the yield.

\section{Materials and methods}


A design of experiments (DOE) was constructed, comprising the main spray drying parameters (Table 1). A full factorial design (Table S1) with one replicate and a center point was created using SAS JMP ${ }^{\circledR} 13$ (SAS Institute, Cary, NC, USA).

Table 1. Spray drying parameters (inlet temperature, atomization pressure, feed rate and aspiration rate), limits and outputs of the DOE design.

Inputs:

\begin{tabular}{lllll}
\hline & Parameter & Low & High & Center-point \\
& Inlet temperature $\left({ }^{\circ} \mathrm{C}\right)$ & 85 & 200 & 142.5 \\
& Atomization pressure & 3.5 & 5 & 4.25 \\
& $\begin{array}{l}\text { Feed rate }(\mathrm{mL} / \mathrm{min}) \\
\text { Aspiration rate }(\%)\end{array}$ & 0.9 & 4.5 & 2.7 \\
Outputs: & 60 & 100 & 80 \\
\hline & Process outputs: & $\begin{array}{l}\text { Outlet temperature and yield } \\
\text { Residual moisture and ease of reconstitution to form an } \\
\text { aqueous dispersion }\end{array}$ \\
& $\begin{array}{l}\text { Particle size and morphology } \\
\text { Hydrated particle outputs: } \\
\text { (reconstituted) }\end{array}$ & & \\
\hline
\end{tabular}

Dimodan ${ }^{\circledR}$ MO 90/D (monoolein) was generously provided by Danisco (Grindsted, Denmark). OVA (Grade VII, from chicken egg white) and dextran (from Leuconostoc spp., $40 \mathrm{kDa}$ ) were purchased from Sigma Aldrich (St. Louis, MO, USA). Purified water (MilliQ, Millipore) was used throughout the study. All other chemicals were of analytical grade and used as received.

A feed emulsion known to be able to generate cubosome precursors after spray drying was prepared as described previously [5]. Briefly, monoolein was dissolved at $5.33 \mathrm{mg} / \mathrm{mL}$ in ethanol. OVA and dextran were dissolved in water at 0.52 and $2.63 \mathrm{mg} / \mathrm{mL}$ and mixed with the ethanolic monoolein at a volume ratio of 3.04:1. This formed an emulsion which was spray dried using air as drying gas on a Büchi B-290 mini spray dryer (Büchi Labortechnik AG, Flawil, Switzerland). The spray dryer was operated in open-loop configuration with a B-296 dehumidifier (Büchi Labortechnik AG, Flawil, Switzerland) and a pressure nozzle with a diameter of $1.5 \mathrm{~mm}$. Each formulation was spray dried according to the parameters specified by the DOE (Table S1).

Yield was evaluated as the weight of the product relative to the dry weight of the feed. Residual moisture was assessed by the weight loss of the powder after a secondary drying step at $57^{\circ} \mathrm{C}$ for 24 $\mathrm{h}$ in a dry atmosphere. The powders ability to redisperse was then evaluated by rehydrating particles at $20 \mathrm{mg} / \mathrm{mL}$ in water by vortexing and grading the dispersion by visual inspection into the categories described in Table 2 . The size (average hydrodynamic diameter) of particles rehydrated at $0.1 \mathrm{mg} / \mathrm{mL}$ in water was measured by dynamic light scattering (DLS) on a Zetasizer Nano ZS (Malvern Zetasizer, NanoZS Zen 3600, Malvern, UK) equipped with a $633 \mathrm{~nm}$ laser and $173^{\circ}$ detection optics at $25^{\circ} \mathrm{C}$. The size was calculated from 3 replicates using the cumulated method with a dispersant viscosity of $0.8872 \mathrm{cP}$. Particle morphology was evaluated by cryogenic transmission electron microscopy (cryo-TEM) using a Tecnai G2 20 TWIN transmission electron microscope (FEI, Hillsboro, OR, USA) as described previously [5]. The experimental results were analyzed with custom written software $\left(\right.$ MATLAB $^{\circledR}$ R2018a, The MathWorks Inc., Natick, MA, U.S.A. The script is available online per Nov. $2^{\text {nd }}, 2018$ : https://doi.org/10.11583/DTU.c.4213148) and with 
SAS JMP ${ }^{\circledR} 13$ using the standard least squares approach and a significance level of $5 \%$. Results are given as mean \pm standard deviation where relevant. For DLS, the minimum mean count rate for individual measurement replicates was $100 \mathrm{kcps}$.

Table 2. Classification scheme for grading the reconstitution properties of spray dried powders.

\begin{tabular}{|ll|}
\hline Grade & Description \\
$\mathbf{0}$ & Clear and transparent liquid with large aggregates \\
$\mathbf{1}$ & Translucent dispersion with easily visible aggregates \\
$\mathbf{2}$ & Cloudy dispersion, aggregates hardly visible \\
$\mathbf{3}$ & Homogeneous milky dispersion, no visible aggregates \\
\hline
\end{tabular}

\section{Results and discussion}

Cubosomes were spray dried using different combinations of spray drying settings to evaluate the influence of these on properties of the produced powder as well as of the rehydrated particles.

Models were fitted to the experimental output data to determine how each output parameter depends on the input parameters. These will be discussed below.

The outlet temperature was well explained by the model $\left(r^{2}=0.96\right.$, Figure $\left.\mathrm{S} 1\right)$. The inlet temperature, aspiration rate and feed rate were significant parameter effects, while their interactions were insignificant (all p-values $\leq 0.010$, Table S3). To control the outlet temperature, the inlet temperature is the most important parameter, but the aspiration rate and feed rate are also influential as shown in Figure 1. Decreasing the inlet temperature and aspiration rate while increasing the feed rate minimizes the outlet temperature.
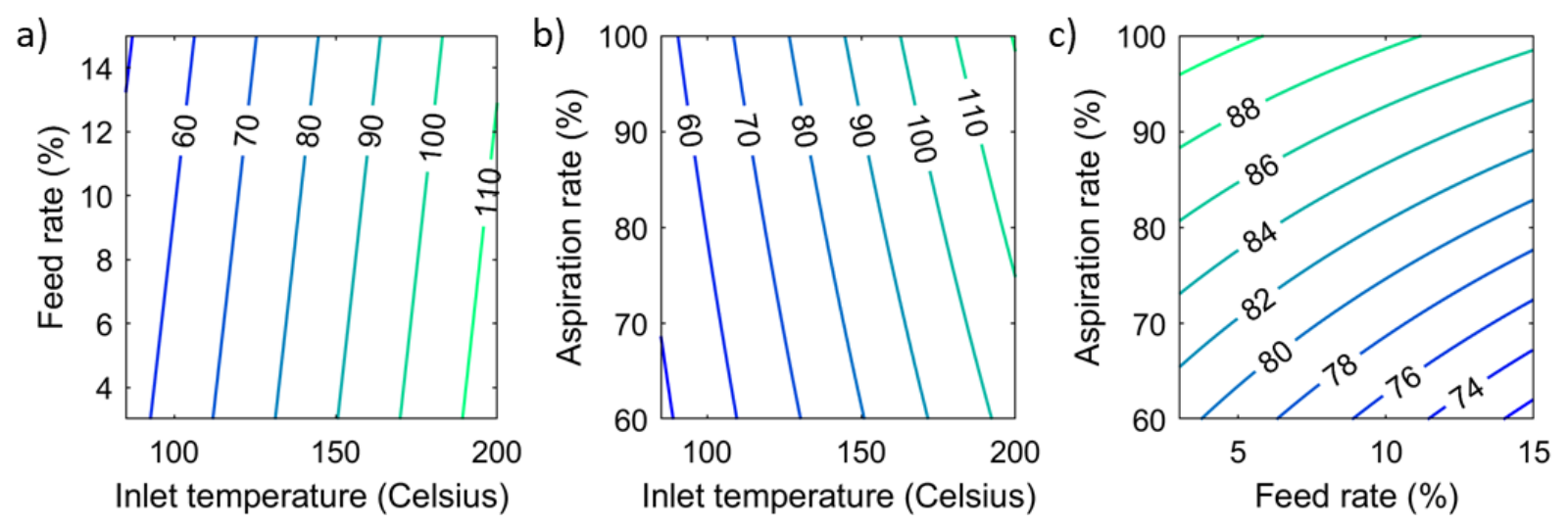

Figure 1. Interactions between parameter effects with significant influence on the outlet temperature. In each figure, the effect of two parameters is shown in the case where all other parameters at kept constant at the center-point value of the DOE. The numbers in the lines indicate the predicted outlet temperature $\left({ }^{\circ} \mathrm{C}\right)$. The interaction effects are not significant (Table S3).

The powder yield was also well explained by the model $\left(\mathrm{r}^{2}=0.96\right.$, Figure S1d) with all parameter effects significant ( $p$-value $<0.001)$ and two significant first order interactions (Table S3). The effect of the parameters are shown in Figure 2. To obtain a high yield, a low atomization pressure and a high aspiration rate combined with a low inlet temperature and a high feed rate is optimal. Low atomization pressure gives larger droplets and should therefore give larger powder particles that are more easily caught in the cyclone. A high aspiration rate results in a larger centrifugal force 
in the cyclone expected to help to sediment the particles. A low inlet temperature and high feed rate can give moist powders, thus artificially increasing the yield. However, the produced powders were all dry (residual moisture $=1 \pm 0.02 \%$, Table S2) and the model describing the residual moisture was insignificant (p-value of 0.372 , Figure S1e). The low inlet temperature and high feed rate may also give a slower drying rate thus giving more time during drying for diffusion and rearrangement of the solids dissolved in the droplet. This might result in denser powder particles [9] and consequently improved sedimentation in the cyclone giving a greater powder yield.

a)

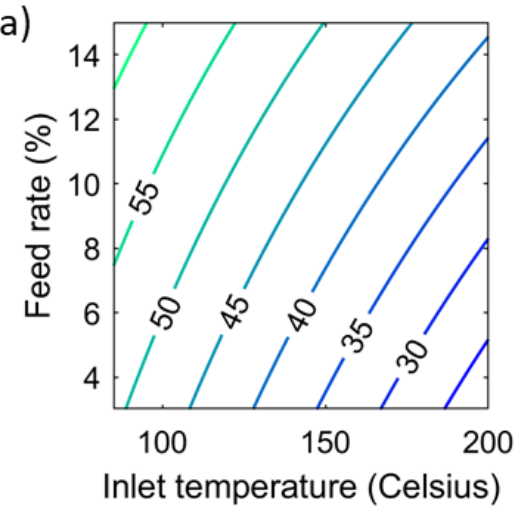

d)

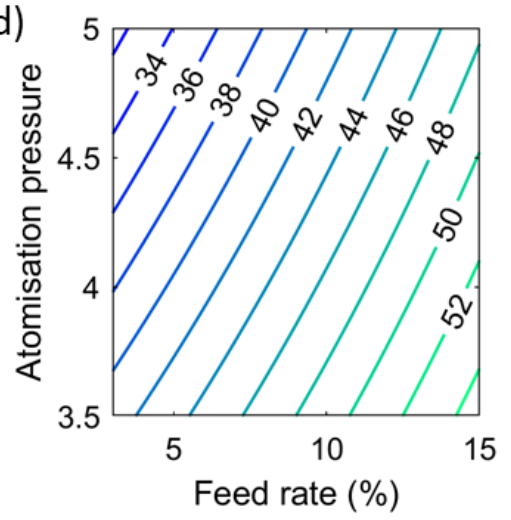

b)

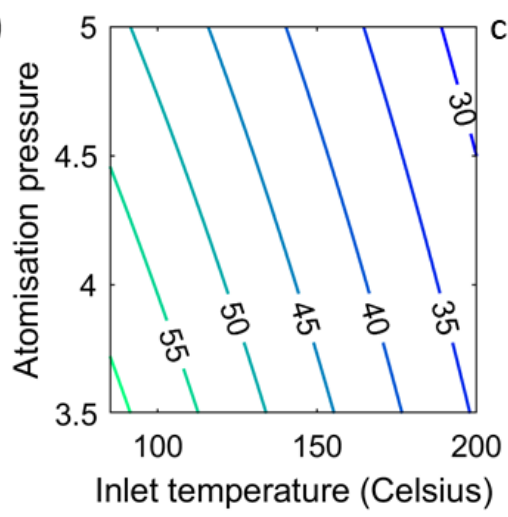

e)

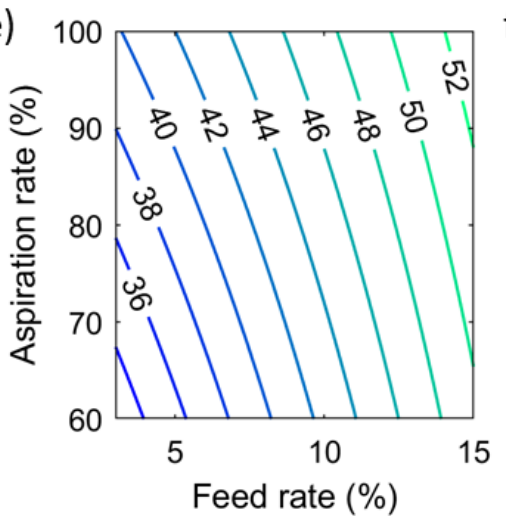

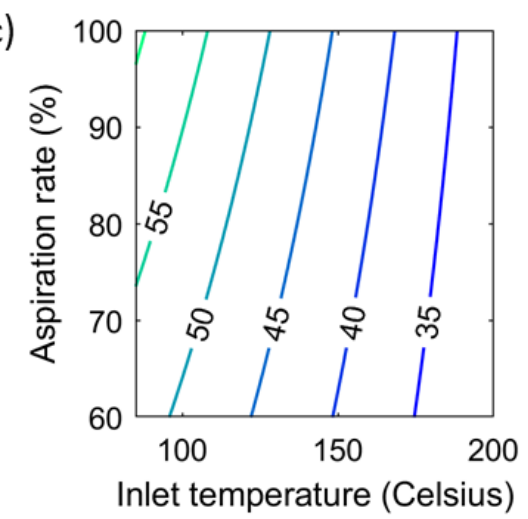

f)

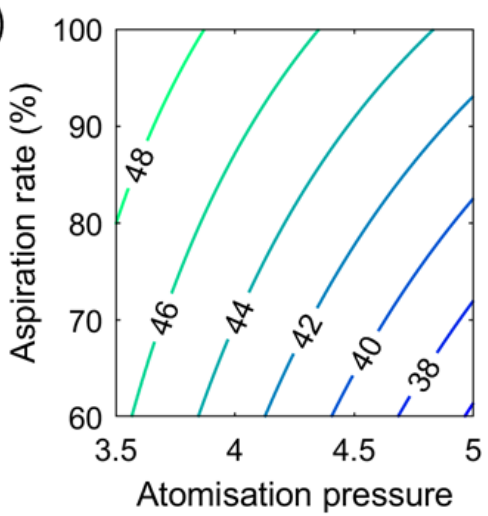

Figure 2. Interactions between parameter effects with significant influence on powder yield. In each figure, the effect of two parameters is shown in the case where all other parameters at kept constant at the center-point value of the DOE. The numbers in the lines indicate the predicted powder yield (\%). The interaction effects in (a) and (c) are significant (p-value of 0.004 and 0.015 , respectively, Table S3), all others are not.

The powders were found to reconstitute and form a dispersion more easily when increased inlet temperature and aspiration rates were used. The model describing this was significant and explained $79 \%$ of the variation in the data ( $p$-value $<0.001$ and $r^{2}=0.79$, Figure S1f). The inlet temperature, aspiration rate and their interaction effect were the only significant parameters (p-value $<0.001$ for both factors and a p-value of 0.016 for their interaction effect, Table S3). The dependence of the reconstitution properties on these parameters is shown in Figure 3. The ease of reconstitution of cubosomes precursors is likely related to a homogeneous distribution of the steric stabilizer (dextran) on the particles [6]. It may therefore be speculated that the fast drying rate resulting from a high inlet temperature and aspiration rate [9] would improve homogeneous distribution of dextran on the particles. 


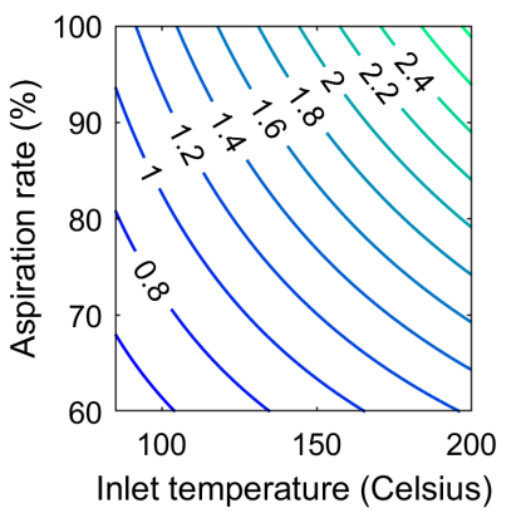

Figure 3. Interactions between parameter effects with significant influence on the ease of reconstitution of the powder. The effect of the two parameters is shown in the case where all other parameters at kept constant at the center-point value of the DOE. The numbers in the lines indicate the predicted powder reconstitution grade. The interaction effect is significant ( $\mathrm{p}$-value of 0.016 ).

Reconstitution of powders in water resulted in dispersions of particles. The size (average hydrodynamic diameter) of the rehydrated particles was approximately $230 \mathrm{~nm}$ in 28 of the total 34 measurements and above $300 \mathrm{~nm}$ for the remaining 6 measurements (Figure 4). The model for particle size had inlet temperature, feed rate and aspiration rate as significant parameter effects ( $p$ value of $0.006,0.032$ and 0.043 , respectively, Table S3). However, the model appeared to be based on an artefact introduced by the great leverage on the model of the above mentioned 6 apparently outlying size measurements (Figure S1b). The effects of the model parameters on the particle size are shown in Figure 5. Interestingly, in all cases with large particle sizes, high outlet temperatures $\left(123-132^{\circ} \mathrm{C}\right)$ were also recorded. Indeed, the same parameter effects that were significant in the model for outlet temperature were also significant in the model for particle size. The outlet temperature showed a threshold at approximately $115^{\circ} \mathrm{C}$ in relation to the hydrated particle size (Figure 6): Below $115^{\circ} \mathrm{C}$, the particle size was $231 \pm 20 \mathrm{~nm}$ (mean $\pm \mathrm{SD}$ ) while above $115^{\circ} \mathrm{C}$, the size was much larger and highly variable $(506 \pm 253 \mathrm{~nm}$, mean $\pm \mathrm{SD})$. To keep the particle size of the cubosomes low and controlled, the outlet temperature should therefore be below $115^{\circ} \mathrm{C}$. 
a )

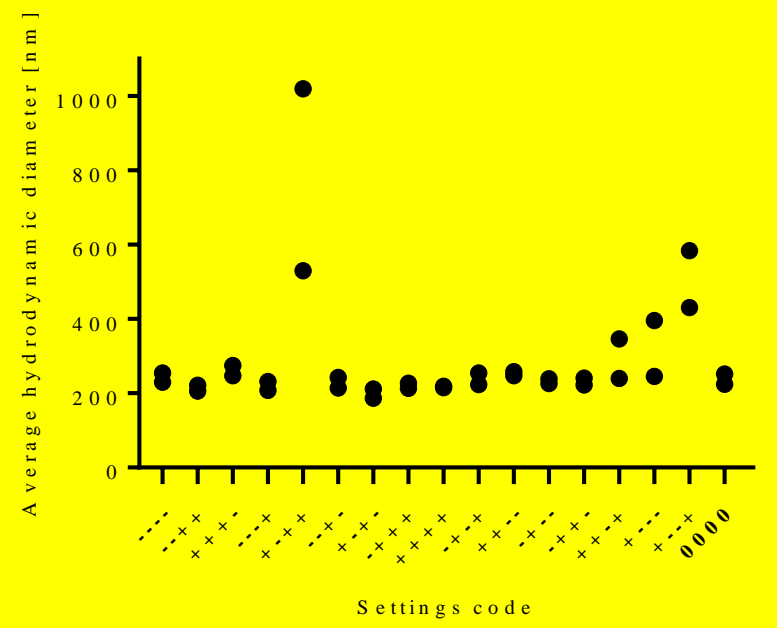

b )

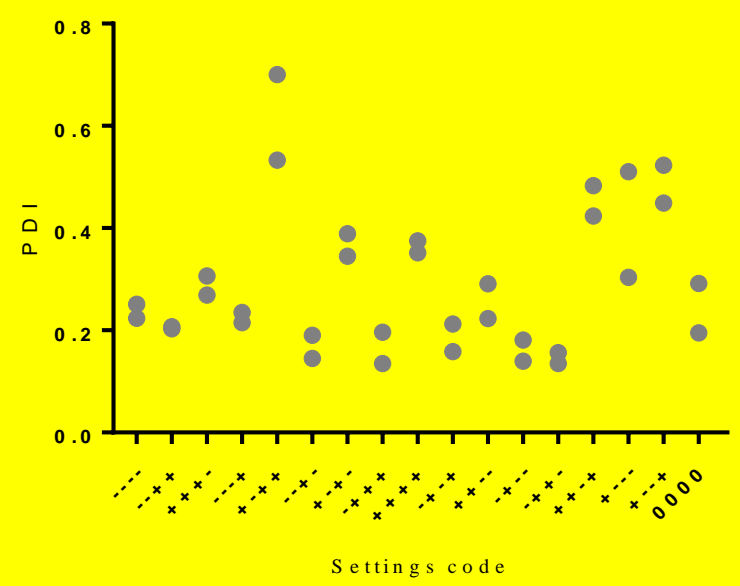

Figure 4. a) Average hydrodynamic diameter and b) PDI of particles obtained with each DOE setting as measured by DLS after rehydrating the powder precursors in water at $0.1 \mathrm{mg} / \mathrm{mL}$.
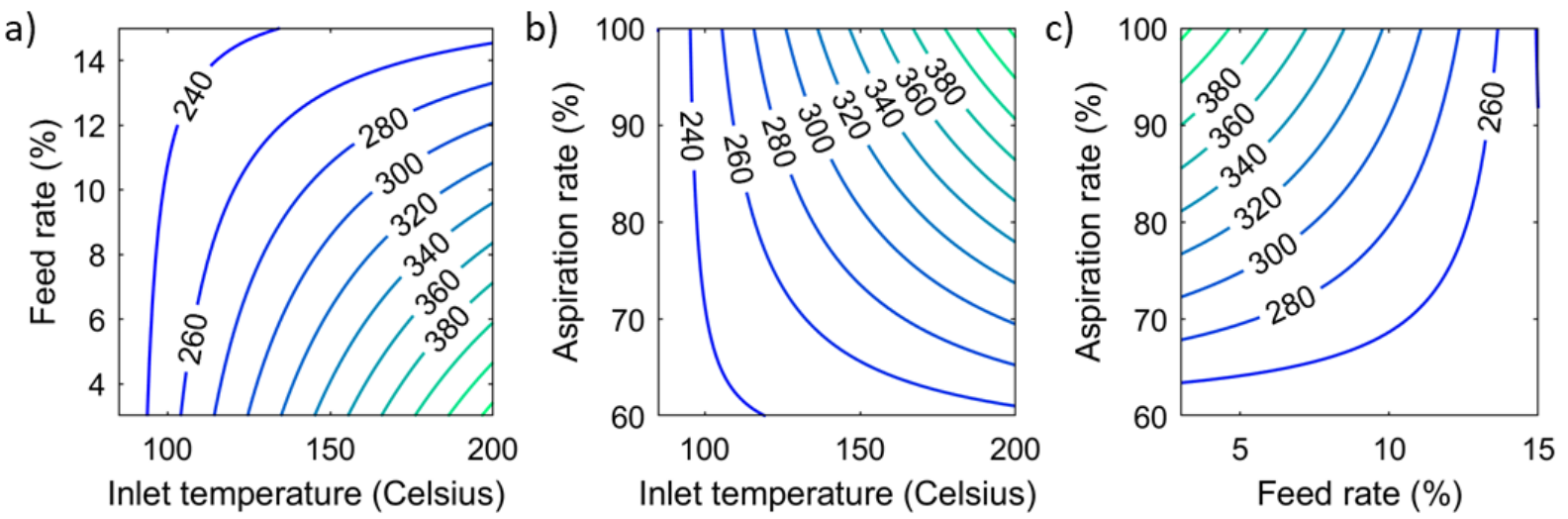

Figure 5. Interactions between parameter effects with significant influence on the size of the rehydrated particles. In each figure, the effect of two parameters is shown in the case where all other parameters at kept constant at the center-point value of the DOE. The labelled lines indicate the predicted outlet temperature $\left({ }^{\circ} \mathrm{C}\right)$ on a) inlet temperature and feed rate, b) inlet temperature and aspiration rate and c) feed rate and aspiration rate. The interaction effects are all significant ( $p$-value of 0.021 (a), 0.022 (b) and 0.033 (c) (Table S3)). 


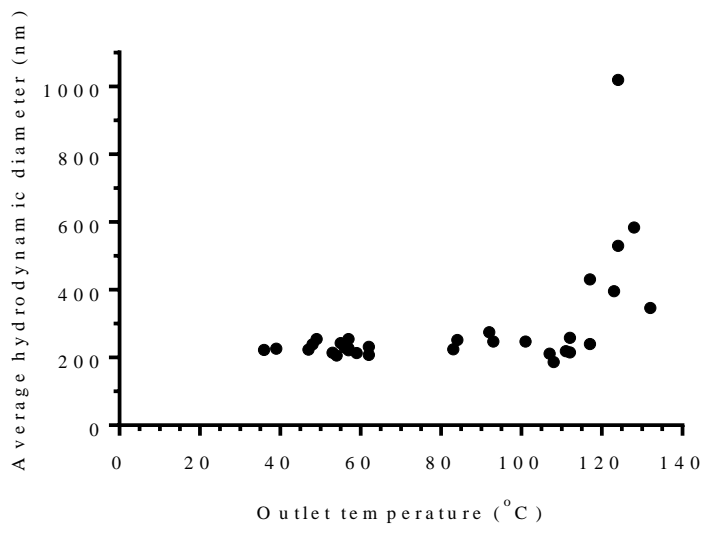

Figure 6. Average hydrodynamic diameter of particles measured by DLS after rehydrating the powder precursors in water to $0.1 \mathrm{mg} / \mathrm{mL}$ vs. outlet temperature of the spray drying process.

Particles morphology can influence the immunogenicity of particulate vaccines [10]. Cubosomes with the model antigen ovalbumin and the adjuvants monophosphoryl lipid A and imiquimod have been reported to stimulate stronger immune responses than similarly adjuvanted liposomes [4]. To evaluate the cubosome content in the dispersions formed by reconstitution of the powders in water, cryo-TEM was employed. Cryo-TEM revealed three types of particles: Dispersed cubosomes, agglomerated cubosomes and dispersed vesicles (Figure 7a, b and c, respectively). Cubosomes were present in all samples and most samples also contained varying amounts of vesicles. The proportion of the total amount of particles that were cubosomes rather than vesicles was estimated, and is referred to as the cubosome content. The average estimated cubosome content found with cryoTEM was $86 \pm 17 \%$ (Table S2). The only significant parameter effect on the determined cubosome content was the inlet temperature ( $p$-value of 0.019, Table S3). An elevated inlet temperature resulted in a slightly higher cubosome content. However, the model was insignificant ( $p$-value of 0.206) explaining only $39 \%$ of the sample variation (Figure S1a). In addition, all samples were replicated once and for every sample with cubosome content below $75 \%$, the replicate had more than $75 \%$ cubosomes. The variation thereby seems associated with the inherently limited particle numbers visualized by cryo-TEM rather than a dependence of particle morphology on spray drying 224 parameters.

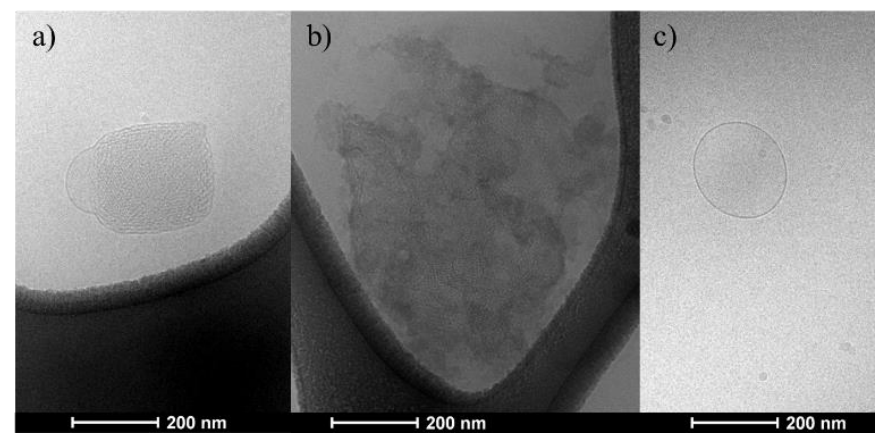

Figure 7. Cryo-TEM images showing the variety of particle morphologies obtained. a) dispersed cubosome, b) agglomerated cubosomes, c) vesicle. 
In total, 19 significant parameter effects and interaction effects were found in this DOE study (excluding the intercepts): Three for the outlet temperature, six for the powder yield, zero for the residual moisture content of the powders, three for the ease of powder reconstitution, six for the average size of rehydrated particles and one for the cubosome content. The calculated false positive discovery rate [11] amongst the effects found to be significant was 1.4. It may therefore be expected that 1 or 2 of the found significant effects is a false positive discovery.

In conclusion, spray drying of cubosomes is a robust method giving low residual moisture, high cubosome contents and consistent size of rehydrated particles within a wide range of parameter settings as long as the outlet temperature is kept below $115^{\circ} \mathrm{C}$. Settings can thus be optimized with regards to obtaining high powder yields, improved reconstitution properties, reduced outlet temperatures or with regards to dry particle engineering considerations.

\section{Acknowledgements}

This work was supported by the Danish National Research Foundation (DNRF122) and Villum Fonden (Grant No. 9301) for Intelligent Drug Delivery and Sensing Using Microcontainers and Nanomechanics (IDUN). Line Hagner Nielsen would like to thank the Danish Research Council for Technology and Production (FTP), Project DFF 4004-00120B for financial support.

The authors would like to acknowledge Mingshi Yang, Department of Pharmacy, University of Copenhagen, for expert advice on the choice and limits of spray drying parameters for the DOE and Nanna Bild, Technical University of Denmark, for the drawing of the schematic. The Core Facility for Integrated Microscopy, Faculty of Health and Medical Sciences, University of Copenhagen is acknowledged for the cryo-TEM studies.

\section{Conflicts of interest}

The authors have no conflicts of interest to declare.

\section{Supporting information}

Table S1: DOE experiments performed

Table S2: Output measurements for each experiment in the DOE

Table S3: Effect of spray drying parameters on outlet temperature, yield, powder product characteristics and physical characteristics of rehydrated particles.

Figure S1: Prediction profiles of the model on the data

https://doi.org/10.11583/DTU.c.4213148: Matlab script used for statistical calculations and generation of figures. 


\section{References}

[1] C. Foged, Subunit vaccines of the future: the need for safe, customized and optimized particulate delivery systems, Ther. Deliv. 2 (2011) 1057-1077. doi:10.4155/tde.11.68.

[2] A.B. Hill, C. Kilgore, M. McGlynn, C.H. Jones, Improving global vaccine accessibility, Curr. Opin. Biotechnol. 42 (2016) 67-73. doi:10.1016/j.copbio.2016.03.002.

[3] P.T. Ingvarsson, S.T. Schmidt, D. Christensen, N.B. Larsen, W.L.J. Hinrichs, P. Andersen, J. Rantanen, H.M. Nielsen, M. Yang, C. Foged, Designing CAF-adjuvanted dry powder vaccines: spray drying preserves the adjuvant activity of CAF01., J. Control. Release. 167 (2013) 256-64. doi:10.1016/j.jconrel.2013.01.031.

[4] S.B. Rizwan, W.T. McBurney, K. Young, T. Hanley, B.J. Boyd, T. Rades, S. Hook, Cubosomes containing the adjuvants imiquimod and monophosphoryl lipid A stimulate robust cellular and humoral immune responses., J. Control. Release. 165 (2013) 16-21. doi:10.1016/j.jconrel.2012.10.020.

[5] C. von Halling Laier, B. Gibson, M. van de Weert, B.J. Boyd, T. Rades, A. Boisen, S. Hook, L. Hagner Nielsen, Spray dried cubosomes with ovalbumin and Quil-A as a nanoparticulate dry powder vaccine formulation, Int. J. Pharm. (2018). doi:10.1016/J.IJPHARM.2018.08.036.

[6] S.B. Rizwan, D. Assmus, A. Boehnke, T. Hanley, B.J. Boyd, T. Rades, S. Hook, Preparation of phytantriol cubosomes by solvent precursor dilution for the delivery of protein vaccines., Eur. J. Pharm. Biopharm. 79 (2011) 15-22. doi:10.1016/j.ejpb.2010.12.034.

[7] L.H. Nielsen, T. Rades, B. Boyd, A. Boisen, Microcontainers as an oral delivery system for spray dried cubosomes containing ovalbumin, Eur. J. Pharm. Biopharm. 118 (2017) 13-20. doi:10.1016/j.ejpb.2016.12.008.

[8] S. Ohtake, R.A. Martin, L. Yee, D. Chen, D.D. Kristensen, D. Lechuga-Ballesteros, V. Truong-Le, Heat-stable measles vaccine produced by spray drying, Vaccine. 28 (2010) 1275-1284. doi:10.1016/j.vaccine.2009.11.024.

[9] T. Sou, E.N. Meeusen, M. de Veer, D.A. V Morton, L.M. Kaminskas, M.P. McIntosh, New developments in dry powder pulmonary vaccine delivery, Trends Biotechnol. 29 (2011) 191198. doi:10.1016/j.tibtech.2010.12.009.

[10] L. Rodrigues, K.N. Raftopoulos, S. Tandrup Schmidt, F. Schneider, H. Dietz, T. Rades, H. Franzyk, A.E. Pedersen, C.M. Papadakis, D. Christensen, G. Winter, C. Foged, M. Hubert, Immune responses induced by nano-self-assembled lipid adjuvants based on a monomycoloyl glycerol analogue after vaccination with the Chlamydia trachomatis major outer membrane protein, J. Control. Release. 285 (2018) 12-22. doi:10.1016/j.jconrel.2018.06.028.

[11] J.D. Storey, The positive false discovery rate: A Bayesian interpretation and the q-value, Ann. Stat. 31 (2003) 2013-2035. doi:10.1214/aos/1074290335. 
Table S1. The parameters of the DOE measurements performed together with the code for each 308 experiment.

\begin{tabular}{|c|c|c|c|c|c|}
\hline $\begin{array}{l}\text { Experiment } \\
\text { no. }\end{array}$ & Code & Inlet temperature $\left({ }^{\circ} \mathrm{C}\right)$ & Feed rate $(\%)$ & $\begin{array}{r}\text { Atomization } \\
\text { pressure }\end{array}$ & $\begin{array}{r}\text { Aspiration } \\
\text { rate }(\%)\end{array}$ \\
\hline 1 & ---- & 85 & 3 & 3,5 & 60 \\
\hline 2 & --++ & 85 & 3 & 5 & 100 \\
\hline 3 & +++- & 200 & 15 & 5 & 60 \\
\hline 4 & ---+ & 85 & 3 & 3,5 & 100 \\
\hline 5 & +-++ & 200 & 3 & 5 & 100 \\
\hline 6 & --+- & 85 & 3 & 5 & 60 \\
\hline 7 & --++ & 85 & 3 & 5 & 100 \\
\hline 8 & +-+- & 200 & 3 & 5 & 60 \\
\hline 9 & -+++ & 85 & 15 & 5 & 100 \\
\hline 10 & ++++ & 200 & 15 & 5 & 100 \\
\hline 11 & -+-+ & 85 & 15 & 3,5 & 100 \\
\hline 12 & +-++ & 200 & 3 & 5 & 100 \\
\hline 13 & +++- & 200 & 15 & 5 & 60 \\
\hline 14 & +-+- & 200 & 3 & 5 & 60 \\
\hline 15 & ---- & 85 & 3 & 3,5 & 60 \\
\hline 16 & 0000 & 142,5 & 9 & 4,25 & 80 \\
\hline 17 & ++-- & 200 & 15 & 3,5 & 60 \\
\hline 18 & -+- & 85 & 15 & 3,5 & 60 \\
\hline 19 & ++-- & 200 & 15 & 3,5 & 60 \\
\hline 20 & -++- & 85 & 15 & 5 & 60 \\
\hline 21 & -+++ & 85 & 15 & 5 & 100 \\
\hline 22 & -+-- & 85 & 15 & 3,5 & 60 \\
\hline 23 & ++-+ & 200 & 15 & 3,5 & 100 \\
\hline 24 & +--- & 200 & 3 & 3,5 & 60 \\
\hline 25 & ++++ & 200 & 15 & 5 & 100 \\
\hline 26 & --+- & 85 & 3 & 5 & 60 \\
\hline 27 & +--- & 200 & 3 & 3,5 & 60 \\
\hline 28 & +--+ & 200 & 3 & 3,5 & 100 \\
\hline 29 & 0000 & 142,5 & 9 & 4,25 & 80 \\
\hline 30 & -++- & 85 & 15 & 5 & 60 \\
\hline 31 & -+-+ & 85 & 15 & 3,5 & 100 \\
\hline 32 & ---+ & 85 & 3 & 3,5 & 100 \\
\hline 33 & ++-+ & 200 & 15 & 3,5 & 100 \\
\hline 34 & +--+ & 200 & 3 & 3,5 & 100 \\
\hline
\end{tabular}

309

310 
311 Table S2. Output measurements for each experiment in the DOE

\begin{tabular}{|c|c|c|c|c|c|c|c|}
\hline $\begin{array}{l}\text { Sample } \\
\text { no. }\end{array}$ & $\begin{array}{l}\text { Input } \\
\text { parameter } \\
\text { DOE } \\
\text { pattern }\end{array}$ & $\begin{array}{r}\text { Outlet } \\
\text { tempera- } \\
\text { ture }\left({ }^{\circ} \mathrm{C}\right)\end{array}$ & $\begin{array}{r}\text { Powder } \\
\text { yield } \\
(\%)\end{array}$ & $\begin{array}{r}\text { Residual } \\
\text { moisture (\% } \\
\text { weight loss on } \\
\text { drying at } \\
\left.56^{\circ} \mathrm{C}\right)\end{array}$ & $\begin{array}{r}\text { Ease of } \\
\text { reconstitu- } \\
\text { tion grade }\end{array}$ & $\begin{array}{r}\text { Average } \\
\text { hydro- } \\
\text { dynamic } \\
\text { particle } \\
\text { diameter } \\
(\mathrm{nm}) \\
\end{array}$ & $\begin{array}{r}\text { Proportion } \\
\text { of hydrated } \\
\text { particles being } \\
\text { cubosomes } \\
\text { (estimate) }\end{array}$ \\
\hline 1 & --- & 49 & 48,71 & 3,2 & 1 & 255 & 0,80 \\
\hline 2 & --++ & 54 & 48,69 & $-1,2$ & 1 & 206 & 0,90 \\
\hline 3 & +++- & 93 & 35,33 & 1,9 & 2 & 247 & 0,90 \\
\hline 4 & ---+ & 62 & 60,83 & $-0,7$ & 1 & 208 & 0,60 \\
\hline 5 & +-++ & 124 & 19,02 & 1,3 & 3 & 529 & 0,90 \\
\hline 6 & --+- & 55 & 39,37 & 2,9 & 0 & 243 & 0,60 \\
\hline 7 & --++ & 57 & 52,66 & $-0,6$ & 1 & 222 & 0,60 \\
\hline 8 & +-+- & 107 & 16,76 & 0,8 & 2 & 212 & 0,50 \\
\hline 9 & -+++ & 59 & 60,86 & 2,1 & 1 & 213 & 0,60 \\
\hline 10 & ++++ & 111 & 39,51 & 0,3 & 3 & 219 & 1,00 \\
\hline 11 & -+-+ & 57 & 68,87 & $-0,1$ & 1 & 255 & 0,60 \\
\hline 12 & +-++ & 124 & 18,37 & 1,9 & 3 & 1019 & 1,00 \\
\hline 13 & +++- & 92 & 34,87 & 1,3 & 1 & 274 & 0,90 \\
\hline 14 & +-+- & 108 & 15,19 & 4,1 & 1 & 186 & 1,00 \\
\hline 15 & ---- & 56 & 59,34 & 2,5 & 1 & 230 & 0,40 \\
\hline 16 & 0000 & 84 & 48,75 & 2,5 & 2 & 252 & 1,00 \\
\hline 17 & ++-- & 101 & 45,59 & 2,3 & 1 & 247 & 0,80 \\
\hline 18 & -+-- & 48 & 62,79 & 0,8 & 0 & 239 & 0,95 \\
\hline 19 & ++-- & 112 & 49,2 & 2,4 & 1 & 258 & 0,90 \\
\hline 20 & -++- & 48 & 54,87 & $-1,9$ & 1 & 241 & 1,00 \\
\hline 21 & -+++ & 57 & 64,63 & 0,9 & 1 & 226 & 0,95 \\
\hline 22 & -+-- & 39 & 61,96 & 1,1 & 1 & 226 & 0,95 \\
\hline 23 & ++-+ & 132 & 40,68 & 1,8 & 3 & 346 & 1,00 \\
\hline 24 & +--- & 93 & 18,83 & 1,4 & 1 & 246 & 1,00 \\
\hline 25 & ++++ & 112 & 40,01 & $-1,6$ & 2 & 215 & 1,00 \\
\hline 26 & --+- & 53 & 37,82 & 0,4 & 0 & 214 & 0,95 \\
\hline 27 & +--- & 123 & 22,67 & 1,2 & 1 & 396 & 0,95 \\
\hline 28 & +--+ & 117 & 28,76 & $-6,9$ & 3 & 430 & 1,00 \\
\hline 29 & 0000 & 83 & 49,6 & 2,2 & 0 & 224 & 1,00 \\
\hline 30 & -++- & 36 & 48,85 & $-1,4$ & 0 & 246 & 0,90 \\
\hline 31 & -+-+ & 47 & 69,52 & 3,8 & 2 & 223 & 0,95 \\
\hline 32 & --+ & 62 & 57,37 & $-1,4$ & 1 & 232 & 0,80 \\
\hline 33 & ++-+ & 117 & 37,72 & 2,9 & 3 & 240 & 1,00 \\
\hline 34 & +--+ & 128 & 29,91 & 3,5 & 3 & 584 & 1,00 \\
\hline
\end{tabular}

312

313 
314 Table S3. Effect of spray drying parameters on outlet temperature, powder product characteristics and physical characteristics of

315 rehydrated particles.

\begin{tabular}{|c|c|c|c|c|c|c|c|c|c|c|c|c|}
\hline \multirow[t]{2}{*}{ Parameter } & \multicolumn{2}{|c|}{$\begin{array}{l}\text { Outlet } \\
\text { temperature }\left({ }^{\circ} \mathrm{C}\right)\end{array}$} & \multicolumn{2}{|c|}{ Powder yield (\%) } & \multicolumn{2}{|c|}{$\begin{array}{l}\text { Residual } \\
\text { moisture in the } \\
\text { powder (\% } \\
\text { weight loss on } \\
\left.\text { drying at } 56^{\circ} \mathrm{C}\right)\end{array}$} & \multicolumn{2}{|c|}{$\begin{array}{l}\text { Ease of powder } \\
\text { reconstitution }\end{array}$} & \multicolumn{2}{|c|}{$\begin{array}{l}\text { Average } \\
\text { hydrodynamic } \\
\text { particle diameter } \\
(\mathrm{nm})\end{array}$} & \multicolumn{2}{|c|}{$\begin{array}{l}\text { Proportion } \\
\text { of hydrated } \\
\text { particles being } \\
\text { cubosomes } \\
\text { (estimate) }\end{array}$} \\
\hline & $\mathrm{SE}^{\mathrm{a}}$ & $\mathrm{PV}^{\mathrm{b}}$ & $\mathrm{SE}$ & $\mathrm{PV}$ & SE & PV & SE & $\mathrm{PV}$ & $\mathrm{SE}$ & PV & SE & $\mathrm{PV}$ \\
\hline Intercept & 82.35 & $<0.001$ & 43.76 & $<0.001$ & 1.00 & 0.010 & 1.41 & $<0.001$ & 288.2 & $<0.001$ & 0.865 & $<0.001$ \\
\hline Inlet temperature $\left({ }^{\circ} \mathrm{C}\right)$ & 29.84 & $<0.001$ & -12.65 & $<0.001$ & 0.26 & 0.492 & 0.63 & $<0.001$ & 61.5 & 0.006 & 0.072 & 0.019 \\
\hline Feed rate $(\%)$ & -3.47 & 0.010 & 7.53 & $<0.001$ & 0.13 & 0.722 & 0.00 & 1.000 & -46.7 & 0.032 & 0.044 & 0.138 \\
\hline Atomization pressure & -1.66 & 0.194 & -4.25 & $<0.001$ & -0.20 & 0.560 & -0.06 & 0.520 & 3.1 & 0.880 & 0.000 & 1.000 \\
\hline Aspiration rate $(\%)$ & 6.47 & $<0.001$ & 2.66 & $<0.001$ & -0.53 & 0.166 & 0.56 & $<0.001$ & 44.0 & 0.043 & 0.013 & 0.665 \\
\hline $\begin{array}{l}\text { Inlet temperature } \\
\left({ }^{\circ} \mathrm{C}\right) * \text { Feed rate }(\%)\end{array}$ & 0.093 & 0.940 & 2.06 & 0.004 & 0.11 & 0.761 & -0.06 & 0.520 & -50.5 & 0.022 & -0.034 & 0.240 \\
\hline $\begin{array}{l}\text { Inlet temperature }\left({ }^{\circ} \mathrm{C}\right) \\
* \text { Atomization } \\
\text { pressure }\end{array}$ & -1.59 & 0.211 & 0.85 & 0.196 & 0.29 & 0.441 & 0.13 & 0.204 & 6.5 & 0.753 & -0.028 & 0.333 \\
\hline $\begin{array}{l}\text { Inlet temperature }\left({ }^{\circ} \mathrm{C}\right) \\
* \text { Aspiration rate }(\%)\end{array}$ & 2.03 & 0.115 & -1.69 & 0.015 & -0.23 & 0.547 & 0.25 & 0.016 & 50.8 & 0.021 & 0.047 & 0.113 \\
\hline $\begin{array}{l}\text { Feed rate }(\%) \\
* \text { Atomization } \\
\text { pressure }\end{array}$ & -1.16 & 0.360 & 0.66 & 0.314 & -0.63 & 0.101 & 0.00 & 1.000 & -12.6 & 0.545 & 0.006 & 0.828 \\
\hline $\begin{array}{l}\text { Feed rate }(\%) \\
* \text { Aspiration rate }(\%)\end{array}$ & 1.22 & 0.335 & -0.89 & 0.178 & 0.75 & 0.053 & 0.00 & 1.000 & -46.6 & 0.033 & -0.025 & 0.389 \\
\hline $\begin{array}{l}\text { Atomization pressure } \\
* \text { Aspiration rate }(\%)\end{array}$ & 0.16 & 0.901 & 1.13 & 0.092 & 0.22 & 0.563 & -0.06 & 0.520 & 17.7 & 0.398 & 0.000 & 1.000 \\
\hline
\end{tabular}

${ }^{\mathrm{a}} \mathrm{SE}=$ Scaled Estimate

$317 \quad$ bPV $=p$-value 
a)

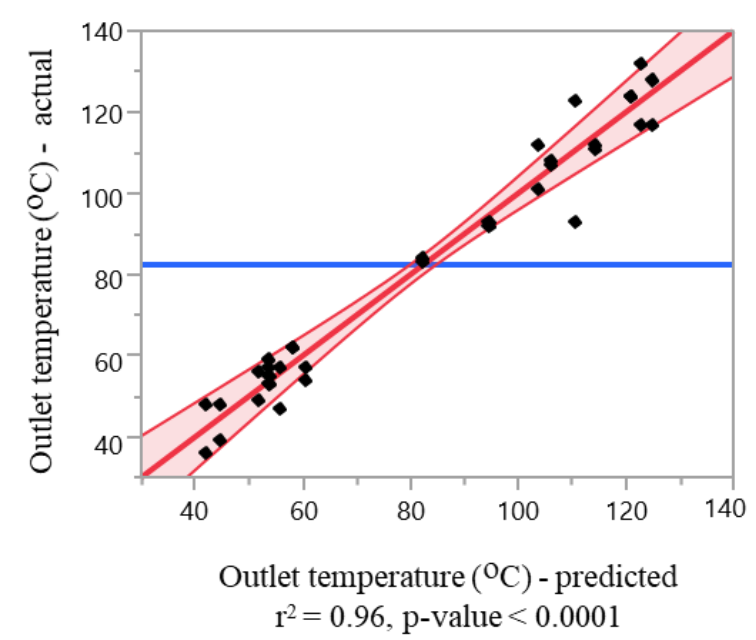

c)

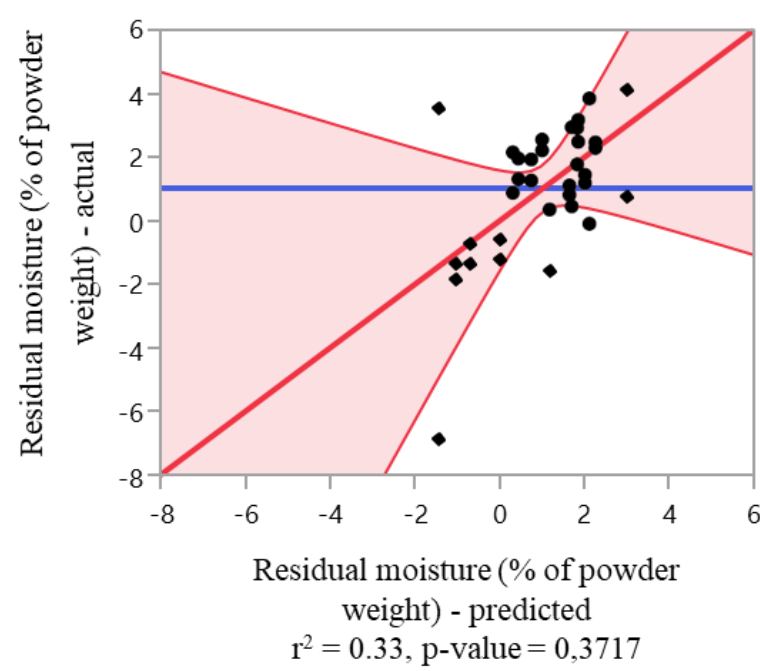

e)

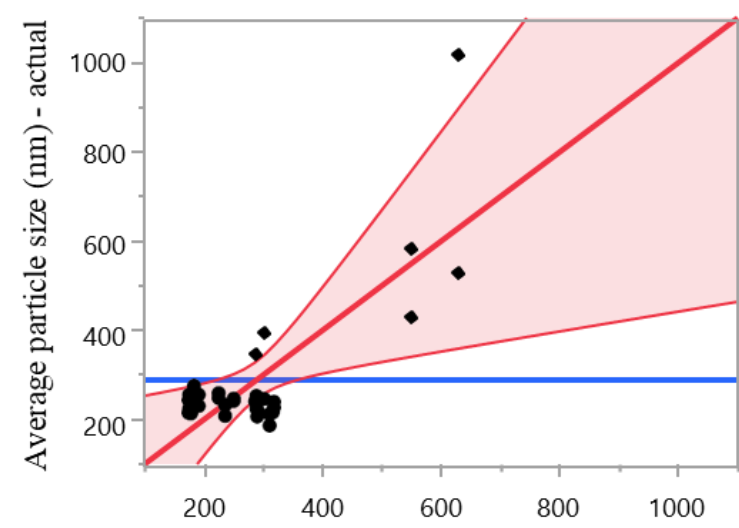

Average hydrodynamic particle diameter $(\mathrm{nm})$ - predicted $\mathrm{r}^{2}=0.62, \mathrm{p}$-value $=0.0043$ b)

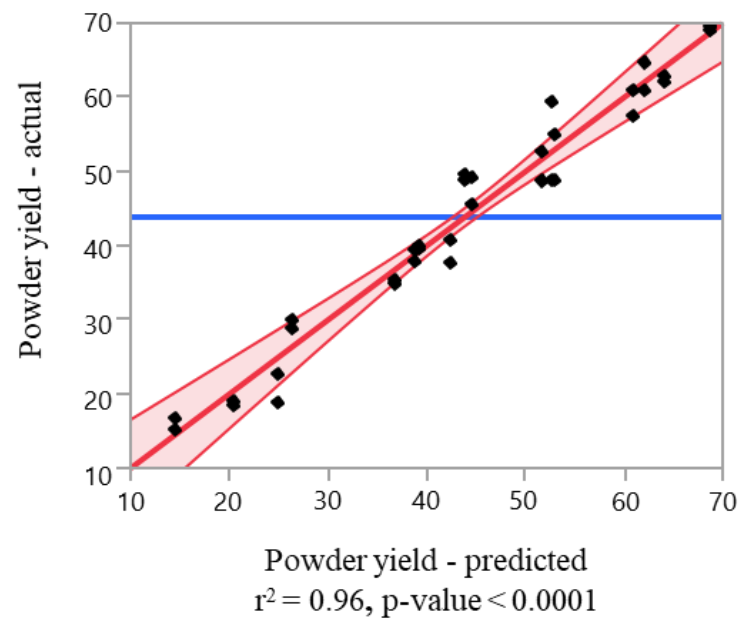

d)

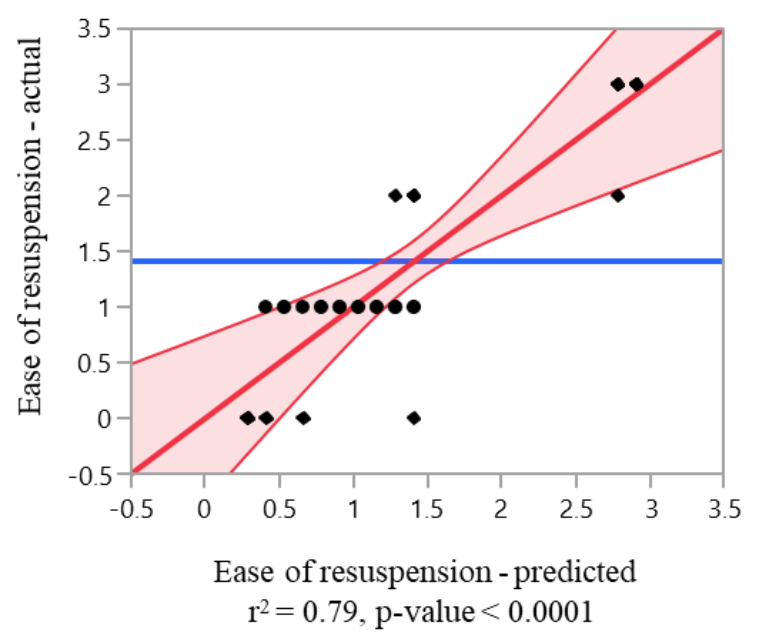

f)

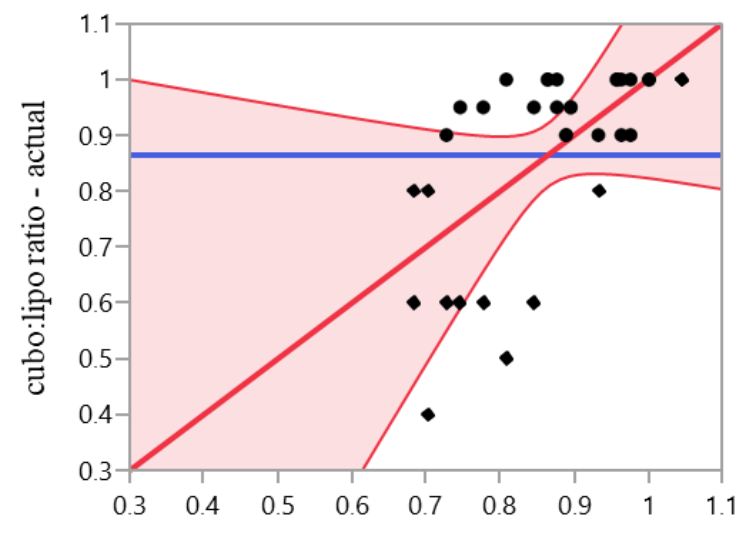

Proportion of hydrated particles being cubosomes - predicted $\mathrm{r}^{2}=0.39, \mathrm{p}$-value $=0.2061$

321 Figure S1. Prediction profiles of a) proportion of particles being cubosomes, b) average particle size, c) outlet temperature, d) yield e) residual moisture in the spray dried powder and f) ease of powder reconstitution. 